\title{
By What Means, By Whose Means?
}

\author{
Alf Rehn
}

Dylan Wittkower has written an elegant argument for revolution in a digital age, but has in doing so also exposed a problematics for analyzing capitalism today. Many are the commentators who in the radical change in how digital goods can be produced and disseminated have seen the seed of a new kind of economic order, and who are now hearing at least the potential death-knell of the old capitalism. The possibility of subverting the entrenched methods of production and distribution has made folk-heroes out of pirates, has made people like McKenzie Wark hail the birth of a "hacker class", and even made business gurus talk in awed tones of people taking the means of production into their own hands. However, in this lauding, there be monsters.

The key issue, for me, in the line of argumentation that Dylan brings forth, is the notion of the means of production. We are all well aware how Marx argued that capitalism works (in part) through a process where these means are appropriated and controlled by a minority of rich individuals, who thus control these as capital. In other words, capital is (in part) synonymous with these means. When the laborer was divorced from them, she became a kind of resource to be exploited, as the ownership over the key element in production was monopolized due to the cost of acquiring the machinery necessary to compete in the milling or the mining trade. Expensive means of production made for a controlled economic order.

Much of the new debates regarding a tentative order of digital economy hinges on the lowered cost of these means. The argument, which Dylan builds on, extends and develops, is that when laptops and storage space becomes so cheap so as to be basically free, the prevailing economic order should start crumbling from its very foundation. And if anyone wants to bicker about how that makes elitist assumptions, just note how quite a few students have received free laptops, how Google makes both storage and processing power exceptionally cheap, point to Linux, and so on. It is a lovely notion, and one that has a lot going for it. We are starting to see an extended economy building on the cheap availability of digital tools, and it would seem the workers are shaking off both their shackles and their alienation, and that there is a tectonic shift happening in the economy.

However, this builds on the assumption that the means of production is a relatively fixed category. Granted, it is infinitely cheaper to buy a laptop and some server-space than it was to buy a small factory. Granted, this creates new possibilities for the person trying to either get into the capitalist game (cf. the fascination for garage start-ups) or to subvert it altogether. But is this enough to assume that the rules of the game have changed? I am not entirely sure.

My counter-argument to Dylan would be something like this:

- When Marx talked about the means of production, he did so building on his materialist philosophy and on the economic logic he saw in his time.

- If we think about what Marx meant with the means of production, the category becomes much more fluid - and the technological interpretation thereof becomes one fixed in a specific context.

- The process of capital depends on capturing the segment of the economic system that has the highest barriers of entry and is easiest to control.

- The concept "means of production" should refer to this (\#3) category, and while it may have been technological at one point, it might be something else today.

- I contend that today, for an analysis of the process of capitalism, the means of production should be understood to refer to a more complex set of means.

I further contend that in the digital economy, the "means of production" in fact should refer to control over the judicial system and over the digital infrastructure/architecture rather than individual technologies. 
In other words, I would challenge Dylan's argument that the means of production have been liberated! While I agree with him as to the specific shifts, my more pessimistic reading is that capitalism has in fact been exceptionally good at responding to them, and that the revolutionary class Dylan identifies might in fact be winning a battle in a war where the other side has already left the war zone. And even though he does point to issues of law and control, there still remains in the article an implicit assumption that the means of production refer to one specific thing: that is, the legal system falls outside of this.

Contemporary capitalism might not even require technological control as long as it can establish control over laws and standards (I will leave the connected discussion about issues such as brands and symbolic control out of this), and may, in fact, celebrate this shift. In an age where IPR is a business model all its own, the hacker with her laptop might, from the viewpoint of contemporary capitalism, be very much like the weaver with her loom, with the only difference being that the weaver was more difficult to embed into the system.

What we need to look at is not "Who controls the technology?" but rather "What is expensive today?" No worker could, in industrial times, afford an industrial drill. Today, a worker can afford a computer. But can a worker afford a lawyer? Can a worker afford three years of litigation? Can a corporation? Note that I am not trying to claim that the judicial apparatus would be the only means of production today, but I am trying to claim that we need a more complex understanding of the concept.

In other words, I would contend that the law has become a critical part of the capitalist process, and an analysis of the means of production needs to take it into consideration. Likewise, we may need to go somewhat further in our analyses of the technologies of production than was possible for Marx.

Consider Amazon and Google. Rather than claiming that their key technology would be the ownership and connected control over specific pieces of technology, both make very clear that they in fact offer an architecture, and that their control of this architecture is in fact what enables them to retain a dominant position. Google has more than 700 datacenters, dispersed globally. Amazon has spent more than two billion USD building an IT infrastructure that it now tries to sell through the concept of "HaaS - Hardware as Service". Both are actively pursuing dominance in cloud computing, something that underlies the idea that soon the "means of production" will be free (or "free"). To overtake this, the worker somehow needs to make the quantum leap from buying a laptop to buying a global infrastructure (and the legal team to go along).

In fact, one might argue that if we look at the purchasing power of the average worker, the situation is, in fact, worse today than it ever was. Even though it might have been nigh impossible for a worker to save enough to buy a small industrial setup (discounting windfalls), there might still have remained an outside chance. The question is, how much money would the contemporary worker need in order to retain the technology, the technological infrastructure, and the legal support to truly capture control over the means of production?

Some would say that this is still easier today, and that guerilla operations feeding off the existence of cheap technology and cloud computing have done great things. I would not contest this. What I will contest is that the movement of a particular kind of means of production to the hands of the many would mean that the means in their entirety are freed. In fact, this might be just what they would want us to believe. Today, there are no fixed means of production, only distributed ones, and we need to ask ourselves "Which one are truly worth controlling?" 